\title{
Inspecting life: professional vision in assisted reproduction technology
}

\author{
Rebecka Arman $^{1}\left[\right.$ [D $\cdot$ Alexander Styhre ${ }^{1}$
}

Received: 10 August 2017 / Accepted: 16 August 2018 / Published online: 29 August 2018

(c) The Author(s) 2018

\begin{abstract}
A growing scholarship in organization studies has examined how visual practices are informed by and situated within organizational settings and routines. Using the concept of professional vision, this is a study of the visual work of embryologists selecting human embryos in the field of assisted reproductive technologies. The term professional vision accentuates how embryologists cope with a number of tensions to accomplish disciplinary objectivity in their work. The study shows how visual practices are simultaneously individual and collective. While there are internationally enacted standard protocols guiding the routine-based work, these are continuously modified as novel clinical data is reported. Therefore, the embryologists' inspection of life needs to actively accommodate both standard cases and deviations therefrom. This ultimately renders the professional vision of embryology something other than an "exact science" but rather a fluid, partly improvised, subjective, and at the same time highly specialized, routinized aesthetic practice. The study contributes to the emerging scholarship on visuality and professional vision in organizations, specifically to how standards are used in such practices. In addition, the study adds to the organizational research on assisted reproduction technology.
\end{abstract}

Keywords Professional vision $\cdot$ Visual practices $\cdot$ Embryology $\cdot$ Assisted reproductive technologies

\section{Introduction}

This article demonstrates how professional vision, being the capacity to align or conflate individual skills and collective ways of seeing in organized and regulated settings, is simultaneously dependent on reproducible standards and protocols. In the field of reproductive medicine, more specifically, what is dependent on and reproduced, is the work conducted by embryologists in in vitro fertilization (IVF) laboratories, i.e., "inspecting human life" in its earliest instances. This renders professional vision an organized and managed visual practice, bound up with standards and the routines for collective verification. Such routines include the IVF laboratory set-up, division of labor, use of technologies and its performance, i.e., its ability to generate pregnancies. The empirical material reported here adds to the growing literature on visual practices and visuality in organization studies (Bell et al. 2013; Styhre 2011; Ewenstein and Whyte 2009), to

Rebecka Arman

Rebecka.arman@handels.gu.se

1 Department of Business Administration, Management Section, School of Business, Economics and Law, University of Gothenburg, Box 610, 40530 Gothenburg, Sweden the literature on professionals and professional work (Currie and White 2012; Suddaby and Viale 2011; Abbott 1988; Freidson 1986), and to the scholarship on reproductive medicine practice. The work of embryologists, granted the professional jurisdictional discretion needed to select the embryos to transfer to the womb, is of interest for students of visual practices and visuality. They represent a medical practice that still, in the era of advanced and highly sophisticated technoscientific medicine, relies on judgment (e.g., Lamont 2009; Zaloom 2006; Benner 1984). This judgment is what Taylor and Hansen (2005: 1213) and Ewenstein and Whyte (2007: 689) call aesthetic knowledge, the capacity to make use of the faculty of vision and forms of know-how that defy formal descriptions. In this case, the aesthetic knowledge is used to select embryos that best comply with the shared, clinically verified and continuously corrected standards established in the clinics.

In reporting this empirical material, the term professional vision (Goodwin 1994) is employed and understood as an analytical concept which fruitfully bridges subjective skills and sensibilities, and shared collective routines for visual inspection. Professional vision includes "ways of seeing," standard protocols directing such visual inspection, and materiality and technologies that generate visual materials 
such as photographic plates or sonograms. In other words, professional vision denotes the totality of the trained and entrenched individual and collective visual skills structuring a professional field of expertise. Such professional vision is of relevance for a variety of activities including the development and monitoring of socio-technical systems such as security screening (Kraemer et al. 2009), in health care practices such as breast cancer screening (Hartswood et al. 2002), or in scientific research work in, e.g., tissue engineering (Vyas 2013). However, the organizational aspects of such professional vision work practices have not been fully addressed in previous studies, an area in which this study seeks to contribute.

Reproductive medicine is a life science discipline that studies the biological mechanisms of ovulation, fertilization, and embryo growth (Watkins 2001; Clarke 1998; Gherardi and Perrotta 2010). In 1978, the first baby fertilized on the basis of what became known as "in vitro fertilization" (IVF) was born in the UK and during the next few years, the new domain of expertise was successfully put to use in a series of countries (Thompson 2005; Franklin and Ragoné 1998). In 2010, Robert Edwards, one of the pioneers of reproductive medicine, was awarded the Nobel Prize in medicine and physiology (Hamberger and Wikland 2010), an event that testified to the success of assisted reproduction as a clinical practice helping millions of despairing couples and (later on) single women become parents. Today, the clinical branch of reproductive medicine - assisted reproduction or IVF-is institutionalized as part of the regular national health services in many OECD countries.

IVF is a complex therapy including several steps and procedures. After the gametes (egg and sperm) have been retrieved, the fertilization is conducted in the laboratory setting by embryologists (a specialist that usually has their basic training as a biomedical scientists). The fertilization is achieved either through what is referred to as in vitro fertilization where egg and sperm are brought together in a test tube, or, in the case of low sperm motility or sperm count, through what is called intra-cytoplasmic sperm injection (ICSI), where the sperm is injected into the egg. After being grown in an incubator, the embryos, in most cases around eight to ten, are inspected by embryologists-first after $25 \mathrm{~h}$, then again at regular intervals. During the inspections, the speed of the division of the cells is controlled to detect any genetic deviations, as well as other possible variations in the visual appearance of the embryo - and one-embryo (or in some countries multiple embryos) is transferred to the uterus after $2-5$ days. The embryologists are thus the professional category at the clinics who visually assess which of the embryos to select, in some cases in dialog with the physicians who are legally responsible for the treatment of the IVF patients. It is important to note that this assessment is not based on any automated or mechanical measurements such as weight or size, or any other biological parameters, but rather, the procedure is entirely based on the visual practices of the community of embryologists.

These visual selection practices have developed, and continue to develop, in combination with historical hard endpoint data, i.e., the number of pregnancies reported after the fact. At the same time, there is much that remains to be known regarding how the embryo connects to the endometrium of the uterus after the transfer, and at times the transfer of embryos exhibiting an appearance associated with low quality still lead to pregnancies, while in many other cases visually verified high-quality embryos are also aborted. Regardless of such difficulties involved in predicting the post-transfer survival rate of embryos, our study will show how embryologists have organized their own professional routines and procedures for their visual assessment work. Their practices are embedded in shared and collective visual competence: A professional embryologist vision. Moreover, their professional practices are an essential organizational resource in IVF-clinics, making this a good case for contributing to the study of professional vision.

The remainder of this paper is structured accordingly: The theoretical framework of the study includes two sections. The first section reviews the literature on professional vision and visuality in organizations. In the second section, studies of professional vision used in assisted conception work and the use of assisted reproduction technology are discussed. Thereafter, the methodology of the study is presented. Fourthly, the empirical material is presented in three sections: first, the aesthetic, improvisational choices and routine-based selection; second, the individual skills and collective standards are examined; the final section addresses the subjective assessment and objective data in informing the embryologists' professional vision. In the final sections of the article, the study's theoretical contributions are presented and discussed.

\section{Professional vision in organizations}

In the Western tradition of thinking, vision and visuality is closely connected to truthfulness and credibility. Words such as "clarity", and "transparency", and expressions such as "a picture is worth a thousand words" or "see for yourself" indicate that the capacity to execute vision, to look and to see, is a privileged human faculty in Western epistemology (Blumenberg 1993; Crary 1990). Not until the midnineteenth century was vision problematized as a form of subjective competence. Studies have shown that vision is less a matter of passively registering external sense impression, but instead is a complex neurological-psychological process integrating the perceptual apparatus and cognitive interpreting capacities. For example, Daston and Galison 
(2007) make a useful distinction between epistemologies of vision, i.e., the totality of shared theoretical and philosophical concerns regarding the possibilities for acquiring knowledge through visual perception, and practices of seeing, the day-to-day work to execute and further develop the professional vision of a community. It is in a similar vein that Goodwin (1994) introduces the term professional vision. This concept bridges epistemologies of vision and the day-to-day work conducted by various professionals on the basis of their visual skills and interrelated resources. ${ }^{1}$

In the life sciences and in health care work (including reproductive medicine and IVF-practices), professional vision is informed by the process of self-correction on the basis of incoming clinical data and evidence. That is, professional vision in, e.g., health care professional work is not so much a matter of individual and collective preferences, in this case as the vision is modified on the basis of reported pregnancies. Yet, visual practices in scientific communities need to be simultaneously individual and collective to accomplish what Timmermans (2008: 170) refers to as disciplinary objectivity, which is accomplished through the "[a]rtful application of insight that comes only with learned experience among peers". This "learned experience among peers" is bound up with the capacity of a specific profession's jurisdictional domains to establish standards and routines for how to visually inspect an entity or a specimen (Timmermans and Epstein 2010; Lampland and Star 2009).

An understanding of standards is thus an essential part of these theoretical concepts. Brunsson et al. (2012: 616) define a standard quite broadly as "[a] rule of common and voluntary use, decided by one or several people or organizations". The role of standards, Timmermans and Berg (1997: 273) argue, is to make actions "comparable over time and space" and to combine resources in meaningful ways when handling local problems. The very term standard thus easily conjures an image of dull and grey administrative routines and accompanying sanctions against deviations therefrom. However, Timmermans and Berg (1997), as well as other scholars (Wright et al. 2012), stress how standards enable creativity and create spaces for collaborative improvisation. Classificatory schemes, especially in scientific practice, are temporarily corroborated, but may be subject to modifications as new data is reported and anomalies accumulate (e.g., "sub-standard" embryos leading to unexpected pregnancies) (Eyal 2013; Navon 2011; Conrad and Potter 2000).

\footnotetext{
${ }^{1}$ Other scholars have proposed similar terms [including Grasseni (2004)] while studying cattle breeders, who uses the terms enskilled vision or skilled vision to underline how visual practices are collective accomplishments. Similarly, Ellis's (2011) study of British naturalists examining moss (the field of bryology) suggests that vision is always already embedded in social relations and "socially aesthetic sensibilities" (Ellis 2011: 772) that structure and inform the gaze, referring to a hegemony of standards.
}

Professional vision includes a variety of know-how, skills, and material resources and can only be acquired through education, practice, and training. Drawing on the work of Ludwik Fleck (1979) and his concepts of thought collectives and thought styles, Daston (2008: 99) suggests that a newcomer to a discipline, in our example in the life sciences, needs to undergo months or even years of training to be able to make credible accounts of what is seen: "The novice sees only blurs and blobs under the microscope; experience and training are required to make sense of this visual chaos, to be able to see things". Studies of the use of visual practices and ways of seeing in, e.g., radiology (Burri 2008), protein crystallography (Myers 2008), and more specifically in the uses of medical visualization technologies such as magnetic resonance imaging (MRI) (Alac 2008; Joyce 2008; Roepstorff 2007), computer tomography (Saunders 2007), and positron emission tomography (PET) (Dumit 2004) demonstrate that the capacity to inspect photographic plates and other media for inscription, is a non-trivial matter demanding substantial training and experience.

In this view, professional vision is heavily "disciplined" in all senses of the term: it is a form of vision both acquired and trained through diligent practice, and it is a vision that is determined by disciplinary boundaries, work organization and categorizations. Hartswood et al. (2002), in their study of visual practices in breast screening argue that standards serve to coordinate assessments between different analysts, at the same time that an independent and credible account is needed to confirm the value of the standard. This makes professional vision what is simultaneously collective and personal, oscillating between intersubjective modes of visuality and ways of seeing based on professional, individual integrity (Hartswood et al. 2002: 95). Timmermans and Berg (1997: 275) use the term local universality to emphasize how real-time work is of necessity via a localized process based on "[n]egotiations and pre-existing institutional, infrastructural, and material relations". The term universal here denotes how such practices can be transferred in time and space on the basis of standards and routines.

To summarize, in the reviewed earlier studies, two interrelated practices have been highlighted which relate to the organization of professional vision. The first is that scientists make use of a "varied set of scientific methods and tools" as a prerequisite to creating and examining "multiple visual representations" (Vyas 2013: 374). The professional vision practices are thus based on the assemblage work of visual technologies and tools. "These all required an active and prolonged handling and manipulation of the biological samples (experimental cell samples) and on-screen models throughout different cell culturing processes". (Vyas 2013: 381) Secondly, when analyzing and communicating research findings, scientists rely not only on "bodily activities such as gestures", (e.g., the physical know-how of using 
the technologies and tools) but also on "external representations" such as charts or notes to make sense out of the visual information (Vyas 2013: 374). In this view, professional vision is always distributed across a set of technologies, tools, practices, notes, scribbles, models, etc., all adding to the analytical work and closely bound up with the scientists' analytical model.

\section{IVF and the embryologist's vision}

The history of reproductive medicine is a story of the development of know-how in a variety of research fields and disciplines including veterinary medicine, gynecology, cytology, microbiology, and experimental medicine at large (Clarke 1998; Harris 1999; Oudshoorn 2003; Franklin and Roberts 2006). Today, after more than three decades, clinically assisted reproduction practices are widely accepted. ${ }^{2}$ However, there are relatively few studies of assisted reproduction practices. One exception is Cussins' (1996, 1998) ethnographic study, in which she suggests that IVF therapy is a process that unfolds as an "ontological choreography". This process includes numerous procedures, routines, technologies, and medical devices that serve to produce the embryos transferred to the uterus or, if deemed unqualified, donated to research work or destroyed (see also Nishizaka 2011). Within these choreographic maneuvers, the specific reproductive material of the embryo plays a central role as being the transitory object between gametes (ova and sperm), the fetus and the living baby (Cussins 1996, 1998).

Being at the threshold between life and non-life (and thus subject to countless moral, ethical, religious, and policy and regulatory debates and decision-making processes), the embryo is, Becker (2000) suggests, an "elusive object". On one hand, the embryo is the carrier of life, a "baby-in-the making" (Svendsen and Koch 2008: 98) and is thus a venerated and sacred object; in sharp contrast, "low quality", "poor", or even "ugly" embryos are subject to the choice between "the dustbin and research" (Svendsen and Koch

\footnotetext{
${ }^{2}$ However, the economic activities pertaining to what Spar (2006) calls the baby business and Goodwin (2010) refers to as the baby market includes practices that remain controversial, including reproductive tourism (Martin 2009; Blyth et al. 2005) and the muchdebated use of commercial gestational surrogacy in, e.g., India (Pande 2010). Many scholars stress the cultural (Inhorn and Birenbaum-Carmeli 2008; Hammons 2008; Mamo 2007) and political (Pfeffer 1999) nature of assisted reproductive technologies (ART). Murphy (2013) speaks about ART as a means for "seizing the means of reproduction" and Waldby and Cooper (2007) refer to what they call the "the biopolitics of reproduction" including forms of "postFordist" biotechnologies. For these scholars, ART is far from uncontroversial and argues that the critique of the expansion and economization of ART should not be muted.
}

2008: 99). Embryologists are the professional group granted the jurisdictional discretion to separate and classify embryos into either of these alternatives.

Consistent with the concept of professional vision, the embryologist's medical gaze (Shaw 2012) is dependent both on specific technologies (i.e., the microscope) that can create reproductive images (Lie 2012) and classificatory schemes (e.g., Heimer 2001) that structure and guide the selection of embryos to transfer to the womb, to freeze (i.e., save for later), or to become "spare embryos" suitable for, e.g., stem cell research. However, as Svendsen and Koch (2008: 98) emphasize, there are no "beautiful embryos" per se, but such statements are bound up with a series of technologies, practices, scientific theories, clinical data, and assumptions put to use in the embryologists' day-to-day work.

Another study by Ehrich et al. (2010) complement Svendsen and Koch's (2008) work by explicitly examining the embryologists' work to select embryos. As "good embryos" have proven to fail when being transferred to the womb, and, conversely, "less good embryos" have produced pregnancies-even though large-scale data still speaks in favor of the good embryos-the selection criteria need to demonstrate a certain degree of fluidity - tolerate room for variation and subjective assessment. At the same time, the selection criteria need to be naturalized, i.e., reach a stage where "some of the complexities of everyday categories become possible to forget or ignore" (Ehrich et al. 2010: 2205).

The embryologists in Ehrich et al. (2010: 2207) study had to cope with the tension between fluidity and the need for stabilization:

[B]oth clinical and embryology staff felt ambivalent about relying too strictly on the grading process...

Fluidity in classifying embryos as worth transferring therefore seemed to some staff a necessary feature of a fair grading system. (Ehrich et al. 2010: 2207)

To modify and improve the accuracy of the classificatory system, embryologists consulted each other regularly to compare their grading of embryos, and in two of the sites studied, "embryologists independently classified a sample of embryos in photographs to compare scores" (Ehrich et al. 2010: 2207).

That is, the embryologists' vision is a professional practice that balances and aligns the tensions between:

- Aesthetic, improvisational choices and routine-based selection.

- Individual skills and collective standards.

- Subjective assessment and objective data.

However, the reviewed studies failed to analyze how these practices were part of organizing the professional vision work, focusing instead mainly on the ethical and 
moral aspects of the selection work, i.e., the non-visual practices being part of the selection work procedure. Relying on the theoretical concept of professional vision and the reviewed previous studies, the empirical material reported in this article seeks to demonstrate how the professional vision of embryologists is both individually and collectively executed in each local laboratory, yet at the same time universalized by standards and routines regarding identification and selection of qualified - at times even described as "beautiful"-embryos.

Using Timmerman and Berg's (1997) term, we will show how the embryologists' vision adheres to local universality, being both subjective without being idiosyncratic, as well as collective and disciplined without being receptive to variation. The embryologists' professional vision is embedded in standards, protocols (e.g., the so-called Istanbul consensus), and routines for inspections. The standards and routines are in turn subject to critical self-correction on the basis of clinical data (i.e., "hard-end data" such as pregnancies and births) that further reinforce and improve the quality of the professional vision. The protocols communicate and represent the visual inspections, yet at the time of the study, other methods and technologies were further developing - as well as competing with - the professional vision practices.

\section{Methodology of the study}

\subsection{Research design and data collection}

The present study is based on a case study design (Stake 1996). Case studies are commonly advocated when there are either few previous studies reported, i.e., there is a need for more contextual understanding of the underlying practices, or when the topic of inquiry is complex, i.e., the field of practice involves many entities and domains of expertise (Eisenhardt 1989). In the case of assisted reproduction clinics, both of these qualifying criteria can be claimed to be fulfilled. The case material here is gathered from 9 out of 16 clinics in the Swedish IVF-field.

The present study included 22 interviewees in different assisted reproduction clinics in Sweden, public as well as private. Several of the interviewees were also researchers in the field of reproductive medicine. We also included an interview with a representative from a company who produces visualizing technology for embryos, used in some of the clinics. The choice of data collection method is consistent with previous studies, e.g., Ehrich et al. (2010: 2205), using interviews with "open-ended questions". The everyday work practices in the different clinics proved to be very similar, probably as a result of many of the "founding fathers" (they were in fact male researchers) of Swedish IVF-clinics having worked in both private and public clinics and having actively participated in collaborations between the clinics. Thus, in this study, each clinic was not seen as a separate case, instead we viewed the field or industry of IVF-clinics in Sweden as one case. In total, at the time of the study (2011-2015) there were six public clinics and ten private clinics in the whole of Sweden. It was estimated that around 150-200 persons were employed in these clinics in toto. For this reason, we chose interviewees from a range of clinics to gain knowledge of as much of the national field as we were given access to. The number of interviewees from each clinic varied from one to six, see Table 1.

The interviewees included directors of clinics, physicians trained as gynecologists and other medical doctors (some of which were professors in university departments in reproductive medicine), embryologists and biochemists (laboratory specialists, here called "embryologists", three of them were also professors). The study included some of the pioneers of assisted reproduction in Sweden, professors in reproductive medicine or gynecology that have both advanced the clinical practice and various technologies and techniques and that have served as entrepreneurs when private clinics were founded in the major cities in the 1980s. Many of the interviewees had extensive experience from the field and told us about how the field has advanced from being something like a curiosity, based on experimental reproductive medicine, to a full-scale, legitimate clinical practice with good clinical efficacy and high patient safety. The sample of interviewees thus included all of the key professional groups operating in the field of assisted reproduction.

In the present paper, which directs the interest to a key procedure in the extensive assisted reproduction therapy, i.e., that of the embryo selection and transfer, much weight is given to one particular group of informants, the embryologists working in the laboratory. In total, ten lab specialists and embryologists - two of which were heads of their clinics-were interviewed, and many of the other interviewees

Table 1 Interviewees by clinic and position

\begin{tabular}{lll}
\hline Clinic & Physicians & $\begin{array}{l}\text { Embryologists } \\
\text { (laboratory spe- } \\
\text { cialists })\end{array}$ \\
\hline$\# 1$ & 2 (1 founder) & $\begin{array}{l}1 \text { (head of lab) } \\
2(1 \text { head of lab) }\end{array}$ \\
$\# 2$ & 1 & 1 \\
$\# 3$ & 3 (2 founders) & \\
$\# 5$ & 3 (2 founders) & 1 \\
$\# 6$ & 1 (founder) & 4 \\
$\# 8$ & 2 & 1 \\
$\# 9$ & 12 & 10 \\
Total & &
\end{tabular}


were working side by side with the embryologists in the clinics and thus also commented on their work. While the interviews with all of the informants played a key role in providing an overview of the clinical practice, the division of labor, the legitimacy of the professional vision work, the general workflow and organization, not all interviewees are represented in this paper with quotes. This may seem like a limited sample, but also "small $\mathrm{n}$ studies" may in fact provide relevant insights regarding, e.g., professional work (for an argument, see March et al. 1991; Steinmetz 2004).

\subsection{Data analysis}

Interviews were transcribed by a professional transcriber and were coded individually by two senior researchers. The interview excerpts were first coded (Strauss and Corbin 1998) on the basis of the basic, empirical content. In the second stage, interview excerpts from the individual interview transcripts were co-located into joint empirical categories. In the third round of coding, these empirical categories were structured into larger "second-order" (i.e., theoretical categories; see Van Maanen 1979) to bridge the theoretical framework and the empirical material (see, e.g., Spradley 1979, Chap. 8). Examples of such codes were "technology development", "policy and regulations", and "scientific practices". These second-order categories were thus used to "emplot" (White 1987) the data into a coherent narrative of how the embryologists align aesthetic improvisational choices with routine-based selection, how the selection is based on individual skills, but also collective standards and finally how the subjective assessment is reconciled with objective data enabling the verification of selection decisions ex post facto has been reported. The data that are of greatest interest are the achieved pregnancies and/or live births.

\section{Embryologists' visual practices}

Guided by our review of the chosen previous literature, we present the interviewee's descriptions of the professional vision practices in three interrelated categories. These show how the embryologists, in relation to the other professions in the clinics, bridge the tensions between: (1) aesthetic, improvisational choices and routine-based selection, (2) individual skills and collective standards and (3) subjective assessment and objective data.

\subsection{Aesthetic, improvisational choices and routine-based selection}

Historically when the first IVF-clinics started, physicians did the work in the laboratory. However, soon the new profession of embryologists specialized in the lab work was developed. One of the pioneers explained that this development had been crucial, because of the specialized knowledge and skills needed: "it is so sophisticated, and it is difficult with so many details, that is clear. And the embryologists' position on the panorama of knowledge has only increased lately, with new developments". (Retired pioneer physician at clinic \#7) The embryologists handle all the laboratory procedures involving the gametes (the reproductive cells), including the fertilization of the egg in in vitro fertilization in the test tube or through the injection of the sperm into the egg (the ICSI procedure), the growing of the embryos in incubators, the selection of embryos, and the freezing and storage of surplus embryos which are not selected for the transfer for later use.

The principal method for selecting the embryo for transfer is morphology analysis (from Greek, morphe, "form"), that is, the visual inspection of the embryo after around 2 days of growth in the incubators. The leader of the lab in clinic \#1 explained that this has been the method used since the very beginning, and even if it has been developed, the basics are still very similar: "Of course as time has gone by, we have learned what to look at, but it has more or less been the same". It is in the laboratories that the key work of IVF-clinics is conducted, this was also recognized by the other professionals at the clinics such as the physicians responsible for the treatments: "The laboratory is very much what IVF is. We make sure the lab has something good to work with, but actually that is where the conception happens and the development of the embryo" (Physician at clinic \#4).

The routineness of the selection procedures and practices were highlighted by many interviewees, yet the "learning what to look at" is a skill that takes time. The interviewees estimated that it takes about 1 year before you can become certified as a fully trained embryologist, and this requires, among other things, having performed a certain amount of selections. Repeating the procedure, making it routine, gives the practice needed: "You need to have a certain volume to become good at what you do, and to sustain the quality and so on" (Physician, clinic \#4). Getting sufficient practice and routine also led to speed, which was a necessary part of making the visual inspections. The decisions are done under time pressure. Since the embryos were grown in incubators designed to recreate the uterus, the embryos were placed under microscopes and inspected outside of heated and protected environments for a minimal amount of time. The assessment thus called for a combination of great carefulness precision, and speed. This is also the case since there are many embryos growing at the same time and a short time windows for when to transfer them back to the womb: "This is a very qualitative type of selection. /.../ In which we have 
got $2 \mathrm{~h}$ to make a decision about which of the embryos that we should be transferring back" (Embryologist \#1).

The demand for speed is related to the improvisational aspect of the aesthetic judgements that the embryologists make. Another interviewee explained the demands for almost instinctual decision-making:

Someone that's good is also someone that's quick at making a decision. Knows what a good embryo is. Has a 'gut feeling' is terrible way to say... but I think, a good embryologist should have an open mind as well, of what can be a pregnancy and what cannot. (Embryologist \#3)

Even if relying on a gut feeling was described as something terrible in this professional setting, having an open mind was necessary since not all cases could be handled as routine. She continued explaining that the patients with no obviously "good" embryos demanded the most improvisation:

When there are fine embryos, it is not the least complicated. But these boundary embryos, can we really justify to put these back? ...We have become more liberal in terms of what we transfer because it is still counted as one attempt [even if no embryo is transferred]. And if we return something, then there is at least a chance. If we transfer nothing, there is no chance at all. (Embryologist \#3)

The absence of visually qualified embryos led at times to crucial/critical discussions. The embryologists debated the vitality of embryos that did not comply with the routine predefined aesthetic parameters: "We don't know everything. Some embryos that we don't think are optimal actually can produce a baby", one embryologist (\#1) said. Regardless of such insights and the knowledge that even "sub-standard embryos" at times led to pregnancies, the embryologists were concerned when only less "beautiful" embryos were available to transfer, testifying to the aesthetic nature of the visual practices:

There is no problem when there are beautiful embryos to transfer, but to select a crappy one, that is not very fun. /.../ Unless the patients ask, though, we try to avoid the topic. If I tell you that this [embryo] wasn't too good but we'll give it back to you anyway, then you might think you're not getting pregnant. (Embryologist \#3)

The aesthetic visual inspection was at times related to what the embryologists "believe in", giving them the finaland to some degree improvised-say: "We have some patients that get no nice ones, and which one to choose in that situation to be able to give her something back? That is the worst part. /.../ [W]e have decided not to transfer anything we do not believe in" (Embryologist \#4).

Being able to combine routine, precision, and speed made experience a key quality in an embryologist. The experience also needed to be combined with a belief in ones' professional vision: "This is where experience matters", embryologist \#2 said. "One may have seen 100 embryos and another may have seen 100,000, and there are these small differences [in perception]. But it is not only a matter of experience; the more you've seen, the more you believe you know".

Another interviewee also pointed to the calculative routine nature of the selection procedures while at the same time being a "game", where improvisation and the unknown is involved. "It's a... numbers game, I choose the best. She gets 10: I choose the best" embryologist \#1 eloquently summarized. Hence, the professional vision practices in this setting involved organizational alignment of both improvisation, when no "beautiful" embryos were easily selected: taking speed, gut-feelings, an open mind and believing in your choice, into account. Yet at the same time, the organization of the practices ensure that they are based on substantial experience, amounts and volume of practice that made it into primarily routine work.

\subsection{Individual skills and collective standards}

The embryologists' work to visually inspect, assess, and select the most suitable embryo was both based in individual skills and competencies and collective practices of visual inspection. While the visual inspection was trained individually, it was always informed by professional vision derived from previous experience and collective standards. That is, while the visual inspection is out of necessity conducted by individual embryologists, their professional vision is constantly subject to collective comparisons and corrections. To accomplish disciplinary objectivity in the embryo selection, the embryologists relied on a system based on international scoring systems which classified similar visual criteria. The embryologists argued that this made it easier to compare embryos with each other, and to communicate within and between clinics. At the time of the study, the most common scale was developed on the basis of the Istanbul consensus ${ }^{3}$, containing the same basic criteria although the scoring systems were sometimes set up differently (going from 1 to 3 , or from 4 to $1, \mathrm{~A}-\mathrm{C}$, etc.). For an example of an overview of one grading system, see Table 2 .

\footnotetext{
3 The standards were agreed upon by an expert panel at an international consensus meeting on oocyte and embryo morphology assessment. The meeting was organized by the international professional organization ESHRE (the European Society of Human Reproduction and Embryology), who also hold exams for the official certification of the title of "embryologist".
} 
Table 2 Consensus scoring system for cleavage-stage embryos, in addition to cell number (Source, Istanbul consensus 2010)

\begin{tabular}{lll}
\hline Grade & Rating & Quality assessment \\
\hline 1 & Good & $<10 \%$ Fragment \\
& & Stage-specific cell size \\
& No multi-nucleation \\
& & $10-25 \%$ fragmentation \\
& Fair & majo-specific cell size for \\
& & No evidence of multi-nucle- \\
& & ation \\
& & Sever fragmentation $(>25 \%)$ \\
& Poor & Cell size not stage-specific \\
& & Evidence of multi-nucleation \\
\hline
\end{tabular}

One of the embryologists explained the visual criteria that are graded and represented in a protocol, based on the collectively developed standards:

We primarily check the number of cells. We select on day two... and by that time, the embryos should have between four and six cells. And then they mustn't be too fragmented, not have a too ugly cytoplasm [The jellylike material that makes up much of a cell inside the cell membrane] and not too uneven size of the cells, which we have a limit on. (Embryologist, \#3, emphasis added)

\section{She continued:}

We look at the cytoplasm in the cells, we look for vacuoles [enclosed cavities in cells] and if there is more than one nucleus [cell center] per cell. And we are looking for something we call a fragment, a form of cellular garbage that can irritate [the embryo].

Figure 1 shows pictures of embryos at the stage of a few days of development, as an example of the types of visual criteria that the embryologists look at. The embryologists made the assessments of all of the criteria in the protocols in the space of a few minutes, for each embryo.

In addition to the above mentioned visual criteria, embryos with cells which divide too quickly, before the 25-27 h range of time, are given a low grade because this may indicate genetic deviation: "If it moves too fast and cleaves to a three cell by the 25 th hour, or a four cell, then it's also an indication of chromosome abnormalities" (Embryologist \#1). In addition, the embryos should preferably divide evenly (into an even number of cells) to comply with the predefined standards (Embryologist \#2).

The list of criteria shows that the embryo is "a dynamic substance", the leader of the laboratory at clinic \#1 pointed out. New technology was being developed to film the embryos inside their heated storage, as they developed to

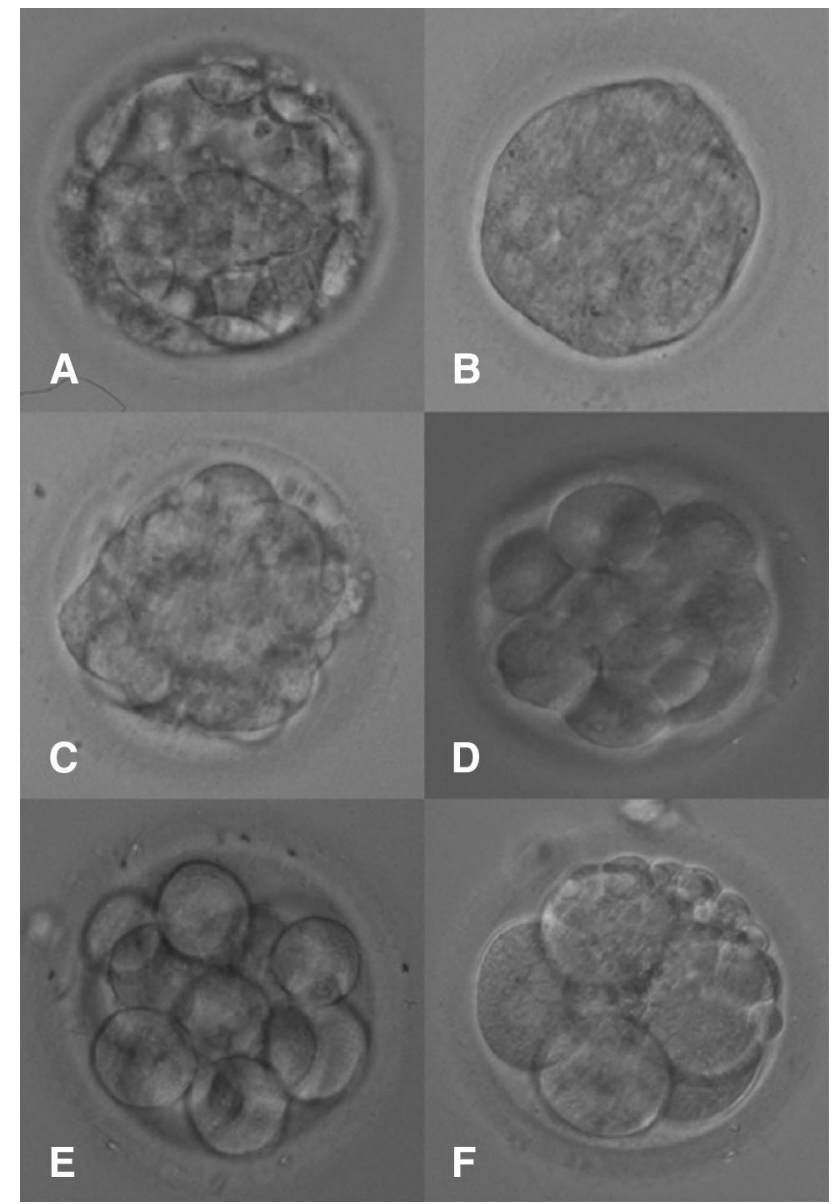

Fig. 1 Images of 4-day-old embryos used to illustrate different grades in a scoring system. Source: Feil et al. (2008), p. 1506, by permission of Oxford University Press

learn whether the timing of events such as cleavage of cells was important:

We can't see the cleavage when we just take them out and look at them and see that they have divided. We don't know if it happened at three in the morning or at seven. Because we can't take them out too many times. (Physician, clinic \#8).

Embryologist \#2 explained one grading system, emphasizing the effects of the most recent international standards for embryo inspection:

Now we're starting to assess vacuoles per se, according to the consensus document, because it appears as if they are negative for the embryo while the granulates don't make any difference. So, that is a new thing to do, on the basis of the article. (Embryologist \#2)

By and large, the principal aesthetic criterion of the embryologist was thus symmetry-the evenness of the cells and the absence of fragments and other esthetically 
disapproved features of the embryos. Yet in using the protocols and grading systems to judge the degree of symmetry, the reliability of the individual's skills was essential. One of the embryologists explained:

It should be very, sort of strict in how they're determining, when they're grading. So, they're always grading the same embryos the same way. (Embryologist \#1)

At the same time that individual skills and experience was highly valued, the inspection of embryos was always a collective procedure. First, in the laboratory, where the day-to-day work was taken care of in teams of two or more embryologists working together and secondly in the joint inspection of embryos in collaboration with other clinics. In one of the clinics (\#1) the physicians also took part in a daily meeting, where the selections were discussed and reviewed on a big screen. The "continual dialogue" within the clinics was highlighted by several interviewees. The capacity to collaborate with others and to have your assessments scrutinized by others were thus important qualities in an embryologist:

You need to be able to appreciate collaboration because you are always dependent on other persons doing their share... In our clinic, we have this routine that we are several participating in the assessment of the embryos, to be able to discuss and share a view, so we're not sliding into completely different opinions. (Embryologist \#2)

Additionally, to calibrate individual and laboratory-based differences in assessment, the different laboratories collaborated to make a joint assessments of embryos:

We do the validation jointly with a few other clinics in Sweden where they have filmed the embryos at different stages... You sit on your own looking at these films and make your assessment... well, looking for different things. [Then] we jointly examine the embryos to see if there were cases where we made different assessments and then we examine them one more time. (Embryologist \#2)

After making their individual assessments, the embryologists discussed differences in assessments and specific features of the embryo that were problematic to reach an agreement on. In the unclear cases, there were more discussions and different embryologists had at times alternative or even opposite views: "In this grey zone, they may have more fragmentation; uneven in size. A few embryos have all these characteristics, you know. They are complicated to assess. Some of us say 'that's good quality!' while others think 'I wouldn't go for that one!'” (Embryologist \#5). Again, it is the embryos deviating from the norm that causes the most discussions: "You notice when we are like five persons looking at the same embryo. And if you have a patient with-how should I put this-somewhat lower quality (of reproductive materials), you notice that we make different assessments compared to the ones we would make if we have a top-quality patient." (Embryologist \#3). She continued to once again emphasize that quick and joint assessments are important:

In the cases which are crystal clear, then there are no problems doing it on your own, but in the questionable cases, it is good this to discuss them with someone. 'Is this about 20 percent fragments or is it more like 30 percent?' 'What can we agree on in this case?' 'Are there two nuclei in this cell or is there just one?' The more eyes that see, the better it is. And then there is the time factor; it is supposed to be done quite fast. /.../We're trying to reach an agreement. (Embryologist \#3)

As the examples show, the protocols and standards made it possible to communicate and discuss the embryos that the individuals looked at and assessed with their professional vision.

"The cells don't answer, they are just there and you have to work with them in the best possible way", the head of the lab in clinic \#2 said. He argued that the collective comparisons between clinics made the treatments more equal in the country, which was good because it should not matter which clinic the patients turned to:

But then always when you are doing a morphological assessment of a living system, there are incredible amounts of variation. That is why it is important that you follow scientific parameters. /.../ This is a system to make sure that it is very similar.

At another clinic (\#3), the physician told us that a computer program was used to feed in the different criteria from the protocols. Based on algorithms, the program then calculated a more exact scoring than was otherwise done by weighing the different criteria together manually.

In summary, the embryologist's professional vision is on the one hand embedded in individual skills in discerning the morphological features of the embryos, and the collective capacity to align and balance individual accounts and professional objectivity through the joint routines for assessing the embryos. The coding schemes and the international standards being enacted here played a key role in determining professional vision practices. However, the standards were ultimately being determined by clinical data, as will be shown in the next section. 


\subsection{Subjective assessment and objective data}

Like in many other scientific communities (see, e.g., Sommerlund 2006: 918), "subjectivity" was the demon of the embryo selection procedure, which needed to be handled properly. This was organized so that embryologists register their subjective assessment in a protocol and eventually then the selection of the embryo can be verified empirically in terms of pregnancy or miscarriage data. Much of the data in Sweden is available in an open access yearly statistical report that compares the results of the clinics in Sweden ${ }^{4}$ : "We know extremely well how we are succeeding. /.../ But there are no big variations [between clinics]." (Physician, clinic \#4).

IVF-clinics collect and examine extensive statistical data on the patients' age and health, but also the morphology of the gametes and embryos at different points in time together with the treatment and lab-protocols followed, and the outcome in the form of pregnancies and live births. Through such data, the embryologists can over time evaluate what kind of appearance embryos have which are more likely to lead to pregnancies and consequently their visual inspection and assessment is verified by clinical data. For the embryologists, they learned after a few days whether their work had led to any pregnancies:

So, you can always look back into the data and everything. /.../ And then we go in and we look in her files and we look at 'what did the embryo look like?' Because we always take a photo of the embryos that we transferred. "What did he look like?" (Embryologist, \#1)

Since the clinical practice in Europe and the Nordic countries stresses the importance of one-embryo transfer to reduce the risks of twin-delivery of the baby, there is particularly good clinical data supporting the visual inspection of individual embryos in these countries:

They transfer more embryos, as they do in the U.S., then you cannot tell which embryo [became the fetus]...so we get a good quality control on what we're doing. (Embryologist, \#2)

Using good methods in the laboratory were described as essential for the clinics' success in producing pregnancies, by all of the professions working at the clinics, since this was the end result the whole clinic was judged by: "Having good people in the lab that can learn these methods so that you can get results, that is what the patients want, they want to become pregnant." (Physician, clinic \#4) Regardless of all the difficulties involved in assessing and selecting embryos

\footnotetext{
$\overline{{ }^{4} \text { See http://www.medscinet.com/q-ivf/. }}$
}

after 2-5 days of growth in the incubator, the embryologists were convinced their expertise made a difference in the end: "I think [our assessment] makes a substantial difference...If you would choose embryos that don't look great at all, then there wouldn't be any good results. So, it really matters." (Embryologist \#2) Another of the embryologists described her role in the industry primarily as being the one who selects which embryo to transfer:

At times there is this weird feeling that 'here I am, making all these selections: this one I accept, that one I wouldn't.' At the same time, we have our reasons for doing this, but still 'who am I to decide?'- those thoughts may come. But we are educated and trained, and who else could make the decision?...It is us working in the lab that take care of them [the embryos] all the time, handling them, and know how they are, based on the knowledge we have today. (Embryologist \#3)

The clinical data supported their choice of embryos complying with predefined standards, yet it also testified to the limited understanding of the biological processes of the post-transfer pregnancy. When collecting the clinical data, low-quality embryos had a lower pregnancy frequency, even though some still led to pregnancy:

Statistically speaking though, these grade-three embryos have been proven to lead to pregnancies but at a lower frequency. So, the chances are not zero. /.../ It is not that complicated to get statistics out of the database, so we retrieved the data and we learned that the pregnancy frequency was between 10 and 15 percent rather than 35 and 40 percent. So, it is definitely not zero. So, if you have nothing else, it is worth trying. (Embryologist \#4)

Perhaps for this reason, the interviewees- the embryologists as well as their physician colleagues at the clinicstestified to an unease in relying on visual assessments, due to their subjective nature and the fact that many unknown factors exist. Many mentioned that there has been much emphasis on and hope for methodological development, e.g., genomics (the screening of the DNA sequence of the embryo) or metabolomics (the measurement of metabolites emitted by embryos into the media in which they grow)

Everyone is looking for something, and what I think is closest in the pipeline in order for us to move forward, or what should be in the pipeline, is better methods for choosing which embryos to transfer back to the womb. That is probably the most important. /.../ Our method today is looking into the microscope. (Physician, clinic \#1)

Also, there were hopes that the new constant videorecording of the embryos inside the incubators would 
reveal new and more objectively verifiable criteria that would improve the rate of pregnancies: "But we saw some embryos, several divided directly from one to three cells. And maybe they will jump back to two and continue the normal cleavage pattern from there, but as soon as you have seen that uneven cleavage, you immediately know that this embryo is not the best one." (Technology company representative). One of the embryologists stressed the problem of working with subjective visual "appearance" over measurable qualities in the work:

We're looking at different morphological characteristics or, you know, appearance. Characteristics of appearance... Everyone else is trying to look for other ways that you can quantify what a good quality embryo is... You can quantify chromosomes, you can quantify RNA production, you can quantify, you know, protein levels. Or you can either, indirectly get an idea of the viability of the embryo, by looking at, when it grows in a culture drop. /.../ And the problem is, developing a technique that can do that, and have it you know, nice and easy to use inside a lab. /.../ So... the whole thing is trying to cut these large technologies down to a small, practical, easy-to-use, solution. (Embryologist \#1)

Thus, despite resting on an international system of criteria, the visual inspections were after all perceived, as another embryologist also argued, as "subjective" and not an "exact science" since nothing was "measured" (Embryologist \#4). Thus, potentially, future advancement of omics analytical technologies may shift the focus from visual inspection and professional vision, but for the time being, the morphology analyses are dominating in the field. Some of the interviewees were more sceptical of the technological and methodological developments: "No one has shown any advantage with those (genetic) diagnostics, compared to just putting back an embryo that looks good." (Physician at clinic \#8). Another of the physicians pointed at the methodological difficulties of moving beyond the morphology analysis of embryos:

One of the reasons for all this emphasis on the embryo is that you can hold it in your hand and study it. /.../ It has been very complicated to intervene and study a woman's womb during pregnancy. (Head of Clinic, Clinic \#4)

To summarize, despite there being considerable research effort that could further strengthen the embryologists' assessment of which embryo to transfer through non-visual measurements; this work still plays a marginal role in the clinical practice. Instead, the individual and collective professional vision of embryologists, embedded in an internationally enacted grading scheme-taking into account clinically relevant parameters-is the principal means for selecting embryos. As a consequence, regardless of the advancement of the field and the clinical performance of assisted reproduction, the professional vision of embryologists, their examination of life-in-the-making, is thus bridging the subjective and objective data. The examination of life is still a matter of diligently combining morphology analysis and clinical data rather than operating on the basis of a more solid theoretical framework. This professional vision is still not anchored in a comprehensive understanding of human reproduction, but organizes practices that handle the fluidity by collectively representing the embryos with the use of stabilizing standards that are understood within the professional community.

\section{Discussion}

Today, assisted reproductive technologies are widespread, resting on solid empirical evidence that testifies to what is considered to be an acceptable level of safety and efficacy of the clinical practices. The entire technoscientific and practico-theoretical field of reproductive medicine and clinical assisted reproduction mobilizes a series of skills, technologies, resources, legal frameworks, and regulatory practices (Styhre and Arman 2015; Waldby and Cooper 2007; Spar 2006; Franklin and Ragoné 1998). Regardless of the development of new bioanalytical methods (genomics, metabolomics, proteomics, etc.), visual skills and know-how in embryonic morphology remain a backbone competence in this part of reproductive medicine. The embryologists themselves, trained in medicine, biology and bioanalytical sciences, address the morphology analysis as a "qualitative method." Yet, they were in fact counting the cells and scoring the degree of grittiness of the cytoplasm and the hard end-point data (i.e., the rate of pregnancies) could be directly connected to the individual embryos selected. The embryos were inspected in terms of the evenness of their cell division, their symmetry and the transparency of the cytoplasm, and while the "textbook cases" caused little disagreement, the lower-grade embryos invoked short but critical discussions. Therefore, the standard protocol which specifies the selection criteria (Svendsen and Koch 2008: 99) in the morphology analysis include a significant element of "fluidity" (Ehrich et al. 2010: 2205), i.e., the classificatory system is designed to accommodate local variation and contingencies. A local universality (Timmermans 2008) was shown to be accomplished by the embryologists and the clinics, being both subjective without being idiosyncratic, as well as collective and disciplined without being receptive to variation.

As the morphology analysis is not, Ehrich et al. (2010: 2207) propose, "an exact science", there is a tension between individual and collective vision and between the standard 
embryo selection criteria and the anomalies being reported. This is because less qualified embryos lead to pregnancies, and the other way around, exemplary embryos fail despite aggregated data suggesting otherwise. What Ehrich et al. (2010: 2210) refer to as the "built moral environment" of the professional community of embryologists must, therefore, reconcile and handle such tensions.

In the study of Ehrich et al. (2010: 2205), they found a process of naturalization in which the complexities became possible to "forget or ignore". Such ignorance or purposeful forgetting was not represented in our interviews, instead the complexities were openly discussed and the responsibility for difficult decisions was often shared. In cases where embryos were rated lower, the embryologists' professional vision to a greater extent became "collective" compared to the unambiguous cases. While subjective differences in degrees are tolerated by the community of embryologists, deviating views regarding the quality of the embryo engendered animated discussions, only to be verified when clinical data regarding pregnancies was provided after the fact.

In line with Daston's (2008) discussion of visual practices as simultaneously being an individual and collective competence, our study shows how the work of embryologists in their professional vision straddle subjective and communal ways of seeing and effectively reconcile the tensions derived therefrom. When embryologists visually inspect the embryos in the Petri dishes, they examine life both as individuals having the skills, training, and the mandate to select embryos, and as members of a professional community being stabilized and institutionalized on basis of the legal and regulatory frameworks, joint professional practices and standard technologies, and the clinical data reported back to the laboratories. In other words, the embryologists' professional vision is subjective, yet always informed and shaped in advance by the standard protocol. The standard protocol itself, subject to continuous modification and correction, contains degrees of fluidity to effectively accommodate outliers that defy the conventional wisdom that "good embryos" are favored over "low-quality embryos". For instance, if there would be no evidence of low-quality embryos in fact leading to pregnancies, then such embryos would have been excluded once and for all.

At the heart of effective professional vision lies the capacity to claim the ability to inspect, e.g., an entity such as an embryo through the lens of disciplinary objectivity (Timmermans 2008). When disciplinary objectivity is accomplished, the professional vision of the embryologist aligns and brings into harmony all the tensions and conditions, which need to be embodied in the ways of seeing that is conducive to qualified embryo selection. This makes professional vision an organized and managed visual practice, including standards and routines for joint seeing. This study, therefore, adds to previous studies of professional vision and embryologists' visual practices an emphasis on organizational activities that either support and reinforce, or, on the contrary, weaken and disqualify collective visual practices. It also adds a case study of professional vision among a group that is essential for this branch of reproductive medicine. That is, professional vision is an organizational resource and accomplishment worthy of further scholarly attention.

\section{Conclusion}

Drawing on the literature on professional vision, this article provides empirical data that shows that embryologists working in assisted reproduction laboratories are educated, trained and continually organized to comply with professional standards and protocols in assessing the embryos grown in incubators. The goal is to accomplish both professional objectivity and good clinical efficacy and safety. This demands that embryologists inspecting and grade the embryos on the basis of a standardized protocol, yet that these maintain openness towards improvisation and unexpected outcomes, i.e., what is not yet accommodated by the protocol. In cases of high quality reproductive materials, there is little controversy, but when all or most embryos from one patient get low scores, there are discussions among colleagues. The embryologists' professional vision is, therefore, both an individual and collective accomplishment and a practice being corrected on the basis of clinical data. The study contributes to the emerging scholarship on visuality and professional vision in organizations, specifically to how standards are used in such practices. In addition, the study adds to the research on assisted reproduction technology, which has also recently been researched by organization studies' scholars (Gherardi and Perrotta 2010).

Acknowledgements Funding was provided by The Swedish Research Council (Grant no. 2012-775).

Open Access This article is distributed under the terms of the Creative Commons Attribution 4.0 International License (http://creativeco mmons.org/licenses/by/4.0/), which permits unrestricted use, distribution, and reproduction in any medium, provided you give appropriate credit to the original author(s) and the source, provide a link to the Creative Commons license, and indicate if changes were made.

\section{References}

Abbott A (1988) The system of professions: an essay on the division of expert labor. Chicago University Press, Chicago

Alac M (2008) Working with brain scans: digital images and gestural interaction in FMRI laboratory. Soc Stud Sci 38(4):483-508

Becker G (2000) The elusive embryo: how women and men approach new reproductive technologies. University of California Press, Berkeley 
Bell E, Samantha W, Schroeder J (eds) (2013) The Routledge companion to visual organization. Routledge, London

Benner P (1984) From novice to expert: excellence and power in clinical nursing practice. Addison-Wesley, San Francisco

Blumenberg H (1993) Light as a metaphor for truth: at the preliminary stage of philosophical concept formation. In: Michael LD (ed) Modernity and the hegemony of vision. University of California Press, Berkeley, pp 30-62

Blyth E, Ferrand A (2005) Reproductive tourism — a price worth paying for reproductive autonomy?. Crit Soc Policy 25(1):91-114

Brunsson N, Rasche A, Seidl D (2012) The dynamics of standardization: three perspectives on standards in organization studies. Organ Stud 33(5-6):613-632

Burri RV (2008) Doing distinctions: boundary work and symbolic capital in radiology. Soc Stud Sci 38:35-62

Clarke AE (1998) Disciplining reproduction: modernity, American life sciences, and the problem of sex. University of California Press, Berkeley

Conrad PO, Potter D (2000) From hyperactive children to ADHD adults: observations on the expansion of medical categories. Soc Probl 47:559-582

Crary J (1990) Techniques of the observer: on vision and modernity in the nineteenth century. The MIT Press, Cambridge

Currie G, White L (2012) Inter-professional barriers and knowledge brokering in an organizational context: the case of healthcare. Organ Stud 33(10): 1333-1361

Cussins C (1996) Ontological choreography: agency through objectification in infertility clinics. Soc Stud Sci 26:575-610

Cussins C (1998) Reproducing reproduction: techniques of normalization and naturalization in infertility clinics. In: Franklin S, Ragoné $\mathrm{H}$ (eds) Reproducing reproduction: kinship, power, and technological innovation. University of Pennsylvania Press, Philadelphia, pp 86-101

Daston L (2008) On scientific observation. Isis 99(1):97-110

Daston L, Galison P (2007) Objectivity. Zone Books, Brooklyn, NY

Dumit J (2004) Picturing personhood: brain scans and biomedical identity. Princeton University Press, Princeton

Ehrich K, Williams C, Farsides B (2010) Fresh or frozen? Classifying 'Spare' embryos for donation to human embryonic stem cell research. Soc Sci Med 71(12):2204-2211

Eisenhardt KN (1989) Building theories from case study research. Acad Manag Rev 14(4):532-550

Ellis R (2011) Jizz and the joy of pattern recognition: virtuosity, discipline and agency of insights in uk naturalists' arts of seeing. Soc Stud Sci 41(6):769-790

Ewenstein B, Whyte J (2007) Beyond words: aesthetic knowledge and knowing in organizations. Organ Stud 28(5):689-708

Ewenstein B, Whyte J (2009) Knowledge practices in design: the role of visual representations as epistemic objects. Organ Stud 30(1):7-30

Eyal G (2013) For a sociology of expertise: the social origins of the autism epidemic. Am J Sociol 118(4):863-907

Feil D, Henshaw RC, Lane M (2008) Day 4 embryo selection is equal to Day 5 using a new embryo scoring system validated in single embryo transfers. Hum Reprod 23(7):1505-1510. https://doi. org/10.1093/humrep/dem419

Fleck L (1979) Genesis and development of a scientific fact. Chicago University Press, Chicago

Franklin S, Ragoné H (eds) (1998) Reproducing reproduction: kinship, power, and technological innovation. University of Pennsylvania Press, Philadelphia

Franklin S, Roberts C (2006) Born and made: an ethnography of preimplantation genetic diagnosis. Princeton University Press, Princeton

Freidson E (1986) Professional powers: a study of the institutionalization of formal knowledge. The University of Chicago Press, Chicago
Gherardi S, Perrotta M (2010) Egg dates sperm: a tale of practice change and its stabilization. Organization 18(5):595-614

Goodwin C (1994) Professional vision. Am Anthropol 96(3):606-633

Goodwin MB (eds) (2010) Baby markets: money and the new politics of creating families. Cambridge University Press, Cambridge

Grasseni C (2004) Skilled vision: an apprenticeship in breeding aesthetics. Soc Anthropol 12(1):41-55

Hamberger L, Wikland M (2010) Nobel prize to Robert Edwards. Acta Obstet Gynecol Scand 89(12):1502-1503

Hammons SA (2008) Assisted reproductive technologies: changing conceptions of motherhood? Affilia J Women Soc Work 23(3):270-280

Hartswood M et al (2002) Performance management in breast screening: a case study of professional vision. Cogn Technol Work 4(2):91-100

Harris H (1999) The birth of the cell. Yale University Press, New Haven

Heimer CA (2001) Cases and biographies: an essay on routinization and the nature of comparison. Ann Rev Sociol 27(1):47-76

Inhorn MC, Birenbaum-Carmeli D (2008) Assisted reproductive technologies and culture change. Annu Rev Anthropol 37:177-196

Joyce KA (2008) Magnetic appeal: MRI and the myth of transparency. Cornell University Press, New York

Kraemer S, Carayon P, Sanquist TF (2009) Human and organizational factors in security screening and inspection systems: conceptual framework and key research needs. Cogn Technol Work 11(1):29-41

Lamont M (2009) How professors think: inside the curious world of academic judgment. Harvard University Press, Cambridge

Lampland M, Leigh SS (eds) (2009) Standards and their stories: how quantifying, classifying, and formalizing practices shape everyday life. Cornell University Press, Ithaca

Lie M (2012) Reproductive images: the autonomous cell. Sci Cult 21(4):475-496

Mamo L (2007) Queering reproduction: achieving pregnancy in the age of technoscience. Duke University Press, Durham

March JG, Sproull LS, Tamuz M (1991) Learning from samples of one or fewer. Organ Sci 2(1):1-13

Martin LJ (2009) Reproductive tourism in the age of globalization. Globalizations 6(2):249-263

Murphy M (2013) Seizing the means of reproduction: entanglements of feminism, health, and technoscience. Duke University Press, Durham

Myers N (2008) Molecular embodiments and the body-work of modelling in protein crystallography. Soc Stud Sci 38:163-199

Navon D (2011) Genomic designation: how genetics can delineate new, phenotypically diffuse medical categories. Soc Stud Sci 41(2):203-226

Nishizaka A (2011) The embodied organization of a real-time fetus: the visible and the invisible in prenatal ultrasound examinations. Soc Stud Sci 41(3):309-336

Oudshoorn N (2003) The male pill: a biography of a technology in the making. Duke University Press, Durham

Pande A (2010) Commercial surrogacy in india: manufacturing a perfect mother-worker. Signs 35(4):969-992

Pfeffer N (1999) The stork and the syringe: a political history of reproductive medicine. Polity, Cambridge

Roepstorff A (2007) Navigating the brainscape: when knowing becomes seeing. In: Grassen C (eds) Skilled vision: between apprenticeship and standards. Berghahn, New York, pp 191-206

Saunders B (2007) CT suite: visual apprenticeship in the age of the mechanical viewbox. In: Grassen C (ed) Skilled vision: between apprenticeship and standards. Berghahn, New York, pp 145-165

Shaw J (2012) The Birth of the clinic and the advent of reproduction: pregnancy, pathology and the medical gaze in modernity. Body Soc 18(2):110-138 
Sommerlund J (2006) Classifying microorganisms: the multiplicity of classifications and research practices in molecular microbial ecology. Soc Stud Sci 36(6):909-928

Spar D (2006) The baby business: how money, science, and politics drive the commerce of conception. Harvard Business School Press, Boston

Spradley JP (1979) The ethnographic interview. Holt, Rinehart and Winston, New York

Stake RE (1996) The art of case study research. Sage, Thousand Oaks

Steinmetz G (2004) Odious comparisons: incommensurability, the case study, and 'Small N's' in sociology. Sociol Theory 22(3):371-400

Strauss AL, Corbin J (1998) Basics of qualitative research, 2nd edn. Sage, London

Styhre A (2011) The architect's gaze: visual artefacts, perception and knowledge in architect work. Cult Organ 17(4):253-269

Styhre A, Arman R (2015) The mutual constitution of legal environments and practices: a case of assisted reproductive technology. Qual Res Organ Manag Int J 10(2):153-174

Suddaby R, Viale T (2011) Professionals and field-level change: institutional work and the professional project. Curr Sociol 59(4):423-444

Svendsen MN, Koch L (2008) Unpacking the 'spare embryo': facilitating stem cell research in a moral landscape. Soc Stud Sci 38(1):93-110

Taylor SS, Hansen H (2005) Finding form: looking at the field of organizational aesthetics. J Manag Stud 42(6):1211-1231

The Istanbul Consensus Workshop on Embryos Assessment: Preceedings of An Expert Meeting, (2010). Human Reproduction. https ://doi.org/10.1093/humrep/der037
Thompson C (2005) Making parents: the ontological choreography of reproductive technologies. The MIT Press, Cambridge

Timmermans S (2008) Professions and their work: do markets shelter or protect professional interests?. Work Occup 35(2):164-188

Timmermans S, Berg M (1997) Standardization in action: achieving local universality through medical protocols. Soc Stud Sci 27(2):273-305

Timmermans S, Epstein S (2010) A world of standards but not a standard world: toward a sociology of standards and standardization. Ann Rev Sociol 36:69-89

Van Maanen J (1979) The fact of fiction in organizational ethnography. Adm Sci Q 24:539-550

Vyas D (2013) Ethnographic notes on visualization practices in tissue engineering research. Cogn Technol Work 15(4):373-388

Waldby C, Cooper M (2007) The biopolitics of reproduction: postfordist biotechnology and women's clinical labour. Aust Fem Stud 23(55):57-73

Watkins ES (2001) On the pill: a social history of oral contraceptives, 1950-1970. Johns Hopkins University Press, Baltimore

White H (1987) The content of form: narrative discourse and historical representation. Johns Hopkins University Press, Baltimore

Wright C, Sturdy A, Wylie N (2012) Management innovation through standardization: consultants as standardizers of organizational practice. Res Policy 41:652-662

Zaloom C (2006) Out of the pits: trading and technology from Chicago to London. Duke University Press, Durham 